EPiC Series in Language and Linguistics
Volume 2, 2017, Pages 60-68
Professional and Academic Discourse:
an Interdisciplinary Perspective

\title{
Cut-offs and Gestures: Analytical Tools to Understand a Second Language Speaker
}

\author{
Renia Lopez-Ozieblo \\ University of Huddersfield, Huddersfield, U.K. \\ renialopez@gmail.com
}

\begin{abstract}
This paper will focus on one specific type of disfluency (speech less than fluent), that is, interruptions or cut-offs. The research on cut-offs has led to various hypotheses explaining how cut-offs are processed: Seyfeddinipur, Kita \& Indefrey (2008) suggested that the cut-off is a controlled action and so on detecting the trouble the stop might be postponed, if necessary, to allow time for the resumption process; Tydgat, Stevens, Hartsuiker and Pickering (2011) added that the stopping and resumption processes are likely to occur concurrently and share the same resources. Therefore, the speaker has to decide whether it is more effective to stop and, if so, where.

In Second Language Acquisition (SLA) error has been the topic of much discussion. However, disfluencies have surprisingly aroused less interest. SLA usually takes the view that any repair following a disfluency is the consequence of linguistic difficulties (usually grammar or vocabulary). However, like among native speakers, there are more reasons for disfluency and repair than just linguistic difficulties.

A tool to aid disfluency analysis is that of the gesture performed together with speech. McNeill's gesture theory holds that gesture and speech are two modalities of the same communicative process and that as such should be analysed together (2012). Therefore, the gesture might provide additional analytical information to the observer.

The objective of this study was to investigate the nature of cut-offs in speakers using their mother tongue and also a second language. As our specific interest is the acquisition of Spanish by English speakers, our results are based on data from 8 participants, 4 Spanish native speakers and 4 Hong Kong students of Spanish as a foreign language (L2). Our results, based on a combination of qualitative and quantitative analysis, indicate that cut-offs, and the gestures associated with them, are used similarly by native speakers of both English and Spanish, including the relationship between the cut-off and the repair or its absence and the gesture. However, the L2 results are very different, showing a significant increase of within-word cut-offs in Hong Kong participants and a decrease among Spanish native speakers. We observed differences in the length and number of pauses after the cut-offs, as well as differences as to the point at which the cut-off occurred in the word. This paper will provide explanations as to the differences observed
\end{abstract}


as well as providing evidence to support some of the existing hypotheses on cut-off production and gesture-speech relationships.

\section{Introduction}

This study originated from the need to better understand the strategies used by Hong Kong (HK) students of Spanish as a foreign language when encountering a conflict in their communicative process. The term conflict is used here to indicate speech trouble (lexical, syntactical or phonetical) but also cognitive difficulties (not remembering an event or not being able to describe it accurately). When speakers encounter conflicts like these, very often they are manifested in their speech, which becomes less than fluent. Disfluencies can be marked by pauses, interruptions (cut-offs), fillers ('uh', 'um' or equivalent), elongations or phonetic changes to vowels (vowel reduction). After the disfluency, the utterance might continue or it might be repaired by adding, deleting, substituting or repeating the original utterance. Disfluencies and their repairs are often just categorised as errors, and yet they might not be errors at all but strategies used by speakers to call the attention of the addressee, to signal a longer pause, or even to aid the addressee to understand the utterance.

Conversation analysis is beginning to recognise that the communication act is much more than just the speech: communication is achieved through a combination of verbal and non-verbal signs. These include gaze, head and hand movements and body posture. (Poyatos, 1993). In particular, the study of hand and arm movements, that is, gestures, is quickly becoming a recognised field within the study of linguistics. A growing number of scholars, Bavelas (1994), Goldin-Meadow (2009), Gullberg, (2003), Kendon (2004), Kita (2000), and McNeill (2000), advocate the importance of the gesture in the speech event as they believe the two (gesture and speech) to originate together, or even to be one unit (McNeill \& Duncan, 2000). If gesture is considered an integral part of speech, the study of disfluencies together with the gesture should provide information as to the nature of the disfluency. The gesture-speech unity is supported by the current findings in more fluent speakers.

\section{Speech Processing and Disfluencies}

During the 1960s and 1970s the study of speech errors led to the proposal of a speech processing mechanism (Fromkin, 1971). This was a serial process with a number of steps from the concept to the articulation. The model was further developed by Levelt (1989) and has been used by gesture scholars to develop dual gesture and speech processing mechanisms that work in parallel (de Ruiter, 1998). However, current neurological research (Banich \& Compton, 2011) is pointing linguists towards a speech processing model that is best described as a parallel activation system (Dell \& Oppenheim, 2012). In this model, nodules are activated and activate others in turn. Those most active are externalised as speech and gesture. This model is represented by McNeill and Duncan's (2000) Growth Point theory, where the gesture and the speech are one unit.

If the study of errors led to the proposal of a speech processing model, perhaps a better understanding of disfluencies and the gestures co-occurring with them will provide more information about second language production processes. In native speakers it is possible that the gestural action might be related to the type of disfluency. It is possible that not all disfluencies are identical. Furthermore, the disfluency might be related to the type of content (Bortfeld et al., 2001) and the cognitive load (Heldner \& Edlund, 2010). This study will focus on the one type of disfluency: cut-offs, which are considered controlled actions in native speakers. They occur when the speaker identifies a better utterance than the one he or she is currently enunciating, resulting in within-word cut-offs (the word is interrupted without having been completed) and followed by no pause or a short one. On the other hand if the speaker comes across 
a conflict but does not have a repair ready, the cut-off is more likely to occur after the word has been completed and the pause will be longer. This behaviour is modelled by the Delayed Interruption for Planning Hypothesis (DIPH) (Seyfeddinipur, 2006; Seyfeddinipur \& Kita, 2001; Seyfeddinipur, Kita \& Indefrey, 2008).

\section{Gestures}

Gestures can be categorised according to their relationship with the content of the speech. For the purposes of this study we have combined various categories into two: iconic - referring to the content of the speech in some way - and pragmatic gestures. Iconic gestures are those that have anaphoric properties or that have some iconicity or metaphoricity -the gesture resembles the idea mentioned in the speech or refers to it indirectly through a movement that depicts a characteristic of the idea. Pragmatic gestures include those used to maintain the rhythm or stress parts of the speech (batons) as well as lexical gestures, those that seem to help retrieve lexical elements or organise the structure of the utterance.

Most of the work done on disfluencies and gestures in second languages has been carried out by Graziano and Gullberg (2013, 2014). They compared gestures in fluent and disfluent speech in Dutch speakers and observed that their participants, learners of French as the L2, performed more gestures during disfluencies than Dutch L1 speakers (Dutch was their mother tongue). The increase in gestures might be related to an increase in gestures of an iconic nature used to elicit help with an unknown word from the addressee (Gullberg, 2014). In lower proficiency levels iconic gestures of a deictic nature (used to indicate) are also more likely, as speakers tend to use more noun phrases and gestures as referents (Gullberg, 1998).

Although disfluencies in English have been widely documented, research data on the Spanish language is considerably lower. Studies of disfluency and gesture together in second language acquisition are even fewer (Graziano \& Gullberg, 2013, 2014).

\section{Objective and Methodology}

The main objective of this study was to compare the use of cut-offs in English and Spanish as L1 and L2 and identify traits common to Spanish native speakers using Spanish that could be explicitly taught to learners of Spanish. As our interest was second language (L2) acquisition, we sought to compare disfluencies and gestures produced in native speakers and learners of Spanish. To assess whether the disfluency and gesture were specific to the L2, it was necessary to create a corpus of first language (L1) data. Therefore, we worked with two groups of participants: one group of HK participants with L1 English and L2 Spanish and a second group of Spanish natives, L1 Spanish and L2 English.

\subsection{Methodology}

In a preliminary study (Lopez-Ozieblo, 2015), it had been ascertained that HK students of Spanish did produce disfluencies and gestures when speaking in Spanish, but it was not known whether these disfluencies and gestures mirrored those of Spanish natives. In order to answer this question an experiment was set up involving native Spanish speakers and HK students. Participants were given three stories, in written, aural and video (no sound) formats and asked to retell them in their L1, either Spanish or English respectively. Then they watched the second part of the video and narrated the events depicted in it in their L2 (English or Spanish). After the retellings there was a short debriefing session in which participants were asked to comment on the exercise, on what input had been the hardest to retell and 
why. The participants were video recorded and these recordings transcribed for both speech and gesture. The participants knew that the object of the research was to asses communication strategies, verbal and non-verbal, but were not aware of the specific interest in hand gesture or disfluencies.

From a total of 28 participants, four Spanish natives and four HK students from each group were chosen. The limiting factor as to the selection was that there were only two HK male participants who spoke the L2 and the study sought gender equality. Each participant narrated three stories in the L1 and one in the L2. In total 32 retellings were used in the analysis, 24 in the L1 and 8 in the L2. The length of the retellings varied, but on average participants spoke for about a minute in each L1 retelling and two minutes in the L2.

The retellings were video recorded (usually with two devices). The speech and the gesture were transcribed using software such as Express-Scribe and Video-Pad Editor. The speech transcriptions were checked with the help of Praat, which allowed us to record accurate pause starting and finishing times, as information on the speech is given in waveform, spectrogram, pitch and intensity graphs. Once the data was manipulated with the help of Excel it was then analysed to identify the cut-offs and gestures by type as well as the resumptions following these disfluencies and the pauses following them. The data on cut-offs was calculated as a rate (cut-off per phonic group per second), it was further subdivided into cut-offs within-word and cut-offs after word completion and the pauses following both were analysed. Gestures occurring with and without disfluencies were also analysed and specifically those occurring with within-word cut-offs were divided according to their relationship with the speech content. If this was of an iconic nature (the gesture representing some part of the speech), gestures were labelled iconic. Otherwise they were labelled pragmatic; and these included gestures to emphasise, mark the rhythm or help the speaker to retrieve a word. Gestures used to answer a physical need (sneezing, scratching) were not included. The repairs recorded were repetitions, deletions, additions or substitutions or a continuation of the utterance. These classifications were based on the work of Clark (1996) in the case of disfluencies and repairs and in the case of gestures on the work by Bavelas (1994), Kendon (2004), McNeill (2000) and Rauschner, Krauss and Chen (1996).

\section{Results and Discussion}

The analysis looked at each participant's production of cut-offs and gestures and compared the results by type of input. It was found that differences in disfluency use, type and frequency and gesture performance might be related to the type of input. Therefore the in-depth analysis used only the data from the L1 and L2 retellings based on the video input to ensure that the type of input was not affecting the results and thus to eliminate a possible variable.

\subsection{Speech Rates}

As the lengths of the retellings varied, the data had to be normalised. In the case of HK participants using the L2, the transcriptions were cut after the description of the third scene (after around three minutes), to ensure manageable data. However, as we were comparing a first with a second language, it was also necessary to account for differences related to proficiency, such as slower speech rate, lower number of words used and longer pauses. Therefore, the frequency of disfluencies and gestures had to be normalised by another variable such as number of words. Current work on disfluency (Colletta, Pellenq \& Cefidekhanie, 2014) suggests that in order to compare speakers with various proficiency levels, it might be more appropriate to use number of phonic groups rather than word count, as phonic groups are less dependent on proficiency. Phonic groups are utterances bound by pauses longer than 200 milliseconds. This seems to be a more consistent reference measure than words when comparing L1 and L2 in the same participants. 
The speech rates - number of phonic groups per second - are higher in HK participants, probably due to the tendency of Spanish speakers to link syllables, thus minimising the number of pauses (Dauer, 1983). In the L1, HK participants' speech is more fluent, faster and with longer utterances than in the L2. Spanish natives produce speech in the L2 quite similar to the L1 (their proficiency level in the L2 was higher than that of HK participants).

\subsection{Types of Input}

The results indicate that there are some differences in speech and gesture depending on the type of input, language and proficiency level. The proficiency level of HK participants in Spanish was lower (A2 CEFR level, Council of Europe, 2001) than that of Spanish natives in English (B2 CEFR level). Therefore, direct comparisons of L2 results (English as an L2 versus Spanish as an L2) are not possible as they are often related to the different levels of proficiency. This has been taken into account in the analysis. Each type of input entails a different cognitive load. As our belief is that speech and gesture are directly linked to cognitive load (Nicoladis, Pika, Yin \& Marentette, 2007, p. 447), it is not relevant - for the purposes of this study - to compare data from retellings based on different input.

\subsection{Cut-offs}

All cut-offs, from all the narrations, were transcribed and further subdivided into those occurring after the word had been completed (after word cut-off) and those interrupting a word (within-word cutoff). Our results for the L1 data supported previous research of a similar nature (Levelt, 1989), showing a prevalence of after-word completion cut-offs (72\% in Spanish natives and 78\% in HK participants). However, in the L2 we observed an increase (to 91\%) of after-word cut-offs in Spanish natives but a decrease to $48 \%$ in HK participants. The Delayed Interruption for Planning Hypothesis (DIPH) (Seyfeddinipur, 2006; Seyfeddinipur, Kita \& Indefrey, 2008) states that speakers are more likely to stop speech only when they have an alternative or a correction ready, resulting in a within-word cut-off. Therefore, more after-word cut-offs are expected in fluent speakers. This is the case in most of the data, except for HK participants in the L2, where there is an increase in within-word cut-offs. These results suggest that HK participants using the L2 are more concerned with correction, while more proficient participants favour fluency. The repair after the cut-off was usually a repetition (in $39 \%$ of all cases), and seldom did the utterance just continue ( $4 \%$ of all cases).

The DIPH predicts that a pause following a cut-off will be shorter in within- word cut-offs (as the correction is ready, which is why the word was interrupted in the first place, at least in fluent speakers). Therefore, we would expect to observe relatively fewer and shorter pauses with within-word cut-offs in the L1, and more within-word cut-offs in the L2. In fluent speakers (whether the language is the L1 or the L2) the pauses following the cut-offs follow the predictions, i.e. shorter pauses with mid-word cutoffs and a repair ready with average lengths of $0.15 \mathrm{~ms}$. in Spanish natives in the L1 and 0.18ms in HK participants in their L1. The average pause length following after-word cut-offs was $0.28 \mathrm{~ms}$. in Spanish natives in their L1 and $0.38 \mathrm{~ms}$. in HK participants in their L1. However, in less fluent speakers (HK participants using their L2) all the pauses were on average much longer, $0.28 \mathrm{~ms}$. and $0.51 \mathrm{~ms}$. respectively. This suggests that the cut-off mechanism might be used differently in less fluent speakers, who prefer immediate interruption as soon as a conflict is detected, even if a repair is not ready. The longer pauses following after-word completion cut-offs could indicate cognitive thinking, be it the formation of an idea or speech processing indeed, the gesture analysis provides some support to this hypothesis.

Thus we believe that the differences observed in the use of cut-offs by HK participants in the L2 are not so much related to differences in the languages (Spanish versus English) but to differences in proficiency levels. One such difference is that HK participants often stuttered in the L2, which would 
have been recorded as a within-word cut-off, even if there was no apparent conflict in the utterance. In higher proficiency speakers stuttering is not as prevalent.

\subsection{Disfluency and Gestures}

Initially all the transcribed data was analysed, fluent and non-fluent speech in all events for a gesturespeech correlation. We were looking for a possible relationship between disfluency and gesture. If the relationship was causal (the disfluency causing the gesture), this would mean more gestures with disfluent speech than with fluent speech. The data revealed that in the group of L1 speakers a gesture was observed (starting, stopping or continuing) in only $41 \%$ of disfluencies, in the Spanish natives, and in $49 \%$ of gestures in HK participants. However, in the L2 of Spanish natives and HK participants these rates went up to $60 \%$ and $65 \%$ respectively. In the L2 there are more disfluencies with gestures than in the L1. Thus, confirming the observations of Graziano and Gullberg (2013, 2014). However, gesture did not usually start with disfluency (as would be expected if there was just a causal relationship between the two).

When analysing gestures only the mid-word cut-offs where considered (to eliminate confusion arising from instances where the gesture would end with the end of the word) -whether the gesture continued, stopped or started. A total of 66 instances were observed (12 among Spanish and 54 among HK participants). New gestures at the point of the interruption only occurred in the L2 of HK speakers in three cases (none in other groups of speakers). The gesture continued only in one Spanish speaker in the L1 but 13 times in HK speakers in the L2 (4 times in the L1). In both Spanish and HK speakers in the L1 there were eight cases of the gesture stopping with the cut-off. There were also three cases in Spanish speakers using their L2 and 26 in HK speakers using their L2. In most cases gesture and speech stop together, supporting the theory of the Growth Point - two modalities forming one unit, controlled by a single processing mechanism. However, in less fluent L2 speakers (the HK participants in the L2) we also observed a number of instances where the gesture continues, or starts during the disfluency, as if the link gesture-speech had been broken or perhaps suggesting a different type of process or a different function to the gesture. This could be that of a pragmatic gesture to aid the verbal production, lexical retrieval, or an iconic depiction of the utterance.

It is important to bear in mind that a number of studies indicate that in cut-offs the gesture stop is more likely to precede the disfluency (Hadar \& Butterworth, 1997; Schegloff, 1984), an event that was not analysed in this study. Our observations indicate that in most cases the gesture is underway when the disfluency occurs and it stops with speech.

If the role of the gesture is to compensate for lack of vocabulary, the expectation would be to see more iconic gestures, the hands drawing the content the speech cannot utter (Gullberg, 2014). Another role of the gesture in the L2 might be referential; Gullberg (2003) proposed that in lower proficiency speakers there might be more referential gestures (deictical) to accompany speech with a preference for nouns. Our results in the analysis of the gesture with the mid-word cut-offs show a preference for iconic gestures only in HK participants using their L1 (8 cases of iconic over 4 pragmatic). In all other categories there seems to be a preference for pragmatic gestures. We observed 24 pragmatic gestures and 18 iconic in HK participants in the L2; 7 pragmatic and 2 iconic in Spanish using their L1 and 2 pragmatic and 1 iconic in the Spanish using their L2.

Further data is needed to test the significance of these results. However, it appears that Spanish natives use more pragmatic gestures to keep the rhythm and to stress elements of the speech. Our belief is that the increase in pragmatic gesture used by HK participants in their L2 is related to lexical retrieval. Lower proficiency speakers use fast repeated gestures such as flipping or circling the hand when encountering lexical difficulties. In these cases, they tend to know the word but cannot retrieve it at the time. These difficulties are different from those experienced in more proficient speech, where a speaker might not know the word at all and seeks help from the addressee by 'drawing' the gesture with his or her hands (Gullberg, 2014), which would result in an iconic gesture. 
It is also possible that HK participants tended to use iconic gestures with fluent speech to ensure that their addressee, whom they knew to be a Spanish native, understood them. To eliminate this possibility, further studies of this nature should ensure the addressee (or confederate) is a native speaker of the same L1 as the participant.

\section{Conclusions}

The analysis of cut-offs leads us to corroborate the work of Seyfeddinipur, Kita and Indefrey (2008), suggesting that fluent speakers are more interested in fluidity than correction. They prefer to interrupt themselves at the end of words, having identified the error and using the time taken to complete the word to process the repair, thus shortening the pauses between cut-off and repair. However, with less fluent speakers, as is the case with our HK participants using their L2, it would seem that the focus is on the correction. These speakers tend to stop as soon as they identify an error, taking as long as necessary to find the repair, and thus producing longer pauses. It would seem that fluent speakers of both English and Spanish used cut-offs similarly, whichever the language.

Our data is not conclusive enough to state the nature of the gesture-speech relationship or to provide support for either of the gesture-speech processing models. However, there seems to be a relationship gesture-speech but it might be different between the L1 and the L2. The relationship gesture-disfluency is not as direct as had been expected: gesture occurs without disfluencies and disfluencies without gestures, particularly in the L1. This suggests that the function of the gesture is much more than just lexical retrieval, supporting the Growth Point Theory of a unity gesture-speech, externalised in the two modalities (Lopez-Ozieblo and McNeill, forthcoming). In the L2, where more disfluencies occur with gestures, especially if the proficiency level is lower, it seems that gestures might indeed be used not only to reduce cognitive load (as might be the case in the L1) but also to help prime the speech processor or even to compensate for the lack of vocabulary.

From these results we cannot categorically state that the gesture type differs by language, Spanish and English, although there is a strong possibility that this might be the case and that Spanish natives use pragmatic gestures more often than HK participants to keep the rhythm and stress speech. However, there does not seem to be a direct gesture-disfluency causal relationship, at least not in the L1.

These results do suggest that the relationship gesture-disfluency might be different in the L2, where more lexical conflicts and higher cognitive loads are likely to occur, and that gesture might be used to aid speech (explaining the cases where gesture started at the start of the disfluency). In the L2 pragmatic gestures might be used more frequently in lower proficiency speakers, in preference to the more useful iconic gestures. Therefore, even if iconic gesture production is not formally included in foreign languages syllabi, attention should be drawn to its usefulness in ensuring successful communication.

A number of ideas for future research have been noted, both in disfluency and in the field of gestures. In particular, we propose to carry on researching the link between cognitive load and disfluency-gesture production.

\section{References}

Banich, M. T., \& Compton, R. J. (2011). Cognitive Neuroscience (3rd ed.). Belmont, CA: Wadsworth.

Bavelas, J. B. (1994). Gestures as part of speech: Methodological implications. Research on Language and Social Interaction, 27, 201-221. 
Bortfeld, H., Leon, S., Bloom, J. E., Schober, M., \& Brennan, S. (2001). Disfluency rates in conversation: Effects of age, relationship, topic, role, and gender. Language and Speech, 44(2), 123147.

Clark, H. H. (1996). Using language. Cambridge, UK: Cambridge University Press.

Colletta, J. M., Pellenq, C., \& Cefidekhanie, A. H. (2014). Age related changes in the processing of bimodal production between 3 and 11 years. Paper presentedat the 6th Conference of the International Society for Gesture Studies. University of California, San Diego, CA.

Council of Europe. (2001).Common European framework of reference for languages: Learning, teaching, assessment. Cambridge, U.K: Press Syndicate of the University of Cambridge.

Dauer, R. M. (1983). Stress timing and syllable timing reanalyzed. Journal of Phonetics, 11, 51 62.

De Ruiter, J. P. (1998). Gesture and speech production. Unpublished doctoral dissertation at Catholic University of Nijmegen, Netherlands.

Dell, G. S., \& Oppenheim, G. M. (2012). Insights for speech production planning from errors in inner speech. In M. Redford (Ed.), Handbook of Speech Production (n.p.). New York, NY: WileyBlackwell.

Fromkin, V. (1971). The Non-anomalous nature of anomalous utterances. In V. Fromkin (Ed.). (1973), Speech errors as linguistic evidence (pp. 215-242). The Hague: Mouton \& Co.

Goldin-Meadow, S. (2009). How gesture promotes learning throughout childhood. Child Development Perspectives, 3, 106-111.

Graziano, M., \& Gullberg, M. (2013). Gesture production and speech fluency in competent speakers and language learners. Paper delivered at TIGER, Tilburg University, Netherlands.

Graziano, M., \& Gullberg, M. (2014). When speech stops, gesture stops: Evidence from crosslinguistic and developmental comparisons. Paper delivered at 6th Conference of the International Society for Gesture Studies, University of California, San Diego, CA.

Gullberg, M. (1998). Gesture as a Communication Strategy in Second Language Discourse: A Study of Learners of French and Swedish. Travaux de l'institut de linguistique de Lund, 35. Linguistics and Phonetics. Unpublished doctoral dissertation. Retrieved from http://lup.lub.lu.se/luur/download?func=downloadFile\&recordOId=18684\&file OId=3912717

Gullberg, M. (2003). Gestures, referents, and anaphoric linkage in learner varieties. In C. Dimroth \& M. Starren (Eds.), Information structure and the dynamics of language acquisition (pp. 311-328). Amsterdam, Netherlands: John Benjamins.

Gullberg, M. (2014). Why gestures are not (only) a compensatory device - evidence from language learners. Paper delivered at 6th Conference of the International Society for Gesture Studies, University of California, San Diego, CA.

Hadar, U., \& Butterworth, B. (1997). Iconic gesture, imagery and word retrieval in speech. Semiotica, 115, 147-172.

Heldner, M., \& Edlund, J. (2010). Pauses, gaps and overlaps in conversations. Journal of Phonetics, 38(4), 555-568.

Kendon, A. (2004). Gesture: Visible action as utterance. New York, NY: Cambridge University Press.

Kita, S. (2000). How representational gestures help speaking. In D. McNeill (Ed.), Language and gesture: Window into thought and action (pp. 162-185). New York, NY: Cambridge University Press.

Levelt, W. J. M. (1989). Speaking: From intention to articulation. Cambridge, MA: MIT Press.

Lopez-Ozieblo, R. (2015). Analysis of disfluencies and gestures in Spanish natives and in students of Spanish as a foreign language. Doctoral thesis (awaiting online publication). Universidad de Malaga, Spain.

Lopez-Ozieblo, R. \& McNeill, D. (forthcoming). Exchange on why we gesture. In R. Church and M. Alibali. Philadelphia, PA: John Benjamins Publishing Co. 
McNeill, D. (2000). Catchments and contexts: Non-modular factors in speech and gesture production. In D. McNeill (Ed.), Language and gesture: Window into thought and action (pp. 312-328). New York, NY: Cambridge University Press.

McNeill, D. (2012). How language began: Gesture and speech in human evolution. New York, NY: Cambridge University Press.

McNeill, D., \& Duncan, S. D. (2000). Growth points in thinking-for-speaking. In D. McNeill (Ed.), Language and gesture: Window into thought and action (pp. 141-161). New York, NY: Cambridge University Press.

Nicoladis, E., Pika, S., Yin, H., \& Marentette, P. (2007). Gesture use in story recall by ChineseEnglish bilinguals. Applied Psycholinguistics, 28, 721-735.

Poyatos, F. (1993). Paralanguage: A linguistic and interdisciplinary approach to interactive speech and sound. Amsterdam, Netherlands: John Benjamins.

Rauscher, F. B., Krauss R. M., \& Chen Y. (1996). Gesture, speech and lexical access: The role of lexical movements in speech production. Psychological Science, 7, 226-230.

Schegloff, E. (1984). On some gestures' relation to talk. In J. M. Atkinson \& J. Heritage (Eds.), Structures of social action: Studies in conversation analysis (pp. 266-296). Cambridge, MA: Cambridge University Press.

Seyfeddinipur, M. (2006). Disfluency: Interrupting speech and gesture. Doctoral dissertation, Radboud University Nijmegen, Nijmegen. Retrieved from

http://hdl.handle.net/11858/00-001M-0000-0013-1B6F-F

Seyfeddinipur, M., \& Kita, S. (2001). Gestures and self-monitoring in speech production. Proceedings of the Annual Meeting of the Berkeley Linguistics Society, 27(1). Retrieved from http://elanguage.net/journals/bls/ article/view/717/576

Seyfeddinipur, M., Kita, S., \& Indefrey, P. (2008). How speakers interrupt themselves in managing problems in speaking: Evidence from self-repairs. Cognition, 108(3), 837-842.

Tydgat, I., Stevens, M., Hartsuiker, R., \& Pickering, M. (2011). Deciding when to stop speaking. Journal of Memory and Language, 64(4), 359-380. 